Review Article

\title{
Snake Venom PLA, a Promising Target for Broad-Spectrum Antivenom Drug Development
}

\author{
Huixiang Xiao, Hong Pan, Keren Liao, Mengxue Yang, and Chunhong Huang \\ Department of Biochemistry, College of Basic Medical Sciences, Nanchang University, Nanchang, Jiangxi Province, China \\ Correspondence should be addressed to Chunhong Huang; chhuang@ncu.edu.cn
}

Huixiang Xiao and Hong Pan contributed equally to this work.

Received 5 September 2017; Accepted 30 October 2017; Published 29 November 2017

Academic Editor: Ji-Fu Wei

Copyright (C) 2017 Huixiang Xiao et al. This is an open access article distributed under the Creative Commons Attribution License, which permits unrestricted use, distribution, and reproduction in any medium, provided the original work is properly cited.

\begin{abstract}
Snakebite envenomation is a neglected global health problem, causing substantial mortality, disability, and psychological morbidity, especially in rural tropical and subtropical zones. Antivenin is currently the only specific medicine for envenomation. However, it is restricted by cold storage, snakebite diagnosis, and high price. Snake venom phospholipase $\mathrm{A}_{2} \mathrm{~s}\left(\mathrm{svPLA}_{2} \mathrm{~s}\right)$ are found in all kinds of venomous snake families (e.g., Viperidae, Elapidae, and Colubridae). Along with their catalytic activity, svPLA ${ }_{2}$ s elicit a wide variety of pharmacological effects that play a pivotal role in envenomation damage. Hence, neutralization of the svPLA $\mathrm{s}_{2}$ could weaken or inhibit toxic damage. Here we overviewed the latest knowledge on the distribution, pathophysiological effects, and inhibitors of svPLA $_{2} \mathrm{~s}$ to elucidate the potential for a novel, wide spectrum antivenom drug targeting svPLA $\mathrm{s}_{2}$.
\end{abstract}

\section{Introduction}

Snakebite envenomation is a critical public health problem and fieldwork hazard, causing high mortality and morbidity, particularly in tropical and subtropical regions. As most ophidian incidents occur in rural areas of developing countries, accurate statistical data concerning the number of victims is difficult to obtain [1]. As extrapolated by Chippaux, worldwide 5,400,000 people are bitten by snakes, 2,500,000 are envenomed, 125,000 die, and more than 100,000 individuals suffer from severe sequelae each year [2]. Unfortunately, snakebite was neglected by governments and international health agencies for a long time, even though the snake bite mortality rate is equivalent to one-fifth of the deaths from malaria worldwide and half of the deaths from HIV/AIDS in India [3]. In 2009 the World Health Organization (WHO) recognized snake bite as a neglected tropical disease [1]. Currently, antivenin is the only specific treatment towards envenomation. Although the immunized animal sera (mainly horse or sheep) presently used are highly effective, they are limited by a few drawbacks [4]. First, local tissue damage resulting from snake venom exposure, often leading to amputation, cannot be reversed by antivenin [4] Furthermore, early and late adverse reactions to antivenin (e.g., anaphylaxis, pyrogenic reactions, and serum sickness) occur in some cases [5]. Additionally, access to antivenins is often limited. Some remote, rural communities where antivenoms are most needed cannot get adequate supplies, due to the lack of cold chain storage and other complex political reasons. Finally, most antivenoms are too expensive for the patient's family in low-income countries [6].

Recently, the nonprofit French drug firm Sanofi Pasteur had ceased the production of Fav-Afrique, the most effective antivenin against Africa's vipers, mambas, and cobras. This has resulted in a large-scale snakebite crisis in rural Africa [7]. This alarming situation demonstrates the need for antivenin replacements and new antivenom drug candidates. This review article focuses on snake venom phospholipase $A_{2} \mathrm{~s}$ $\left(\operatorname{svPLA}_{2} s\right)$, a chemical family that is widely distributed in venomous snake species. Here we describe $\operatorname{svPLA}_{2} \mathrm{~s}$, the antienvenomation effects of their inhibitors, and the potential of being a common target for broad-spectrum antivenom drugs.

\section{Characteristics of svPLA}

Snake venoms are complicated mixtures, consisting of phospholipase $\mathrm{A}_{2} \mathrm{~s}$, metalloproteases, C-lectins, serine proteases, 
L-amino acid oxidases, disintegrins, and a few other compounds [1]. Most svPLA 2 s hydrolyze glycerophospholipids at the sn-2 position of the glycerol backbone, freeing lysophospholipids, and fatty acids. svPLA 2 s share 44-99\% amino acid identity in their primarily structure, which results to high similarity in their tertiary structure [8]. Based on their size, location, function, substrate specificity, and calcium requirement, $\mathrm{PLA}_{2} \mathrm{~s}$ are classified into six families. $s v \mathrm{PLA}_{2}$ belongs to the secretory $\mathrm{PLA}_{2}\left(\mathrm{sLA}_{2}\right)$ family (groups IA, IIA, and IIB) [9-11]. Cobras and kraits, rattlesnakes, and Gaboon vipers have svPLA $A_{2} s$ in groups IA, IIA, and IIB, respectively [8]. There are also group IB enzymes which are mainly found in mammalian pancreas that have been reported in some snake venoms, such as Oxyuranus scutellatus [12], Pseudonaja textilis [13], and Micrurus frontalis frontalis [14]. These compounds are conserved in structure and have similar molecular masses ( 10-20 kDa), 5-7 disulfide bonds, and analogous three-dimensional structures [15]. In Group I there are approximately 115-120 residues, 7 disulfide bonds (the unique disulfide linking residues 11 and 77), and G IA has a characteristic surface loop between residues 63 to 67 called elapidic loop [11]. While G IB has a five amino acids residues (residues 62-67) extension termed pancreatic loop, some G IB snake venom $\mathrm{PLA}_{2}$ even has an eight-residue propeptide segment in their mature state $[13,16]$. In contrast, Group II has a C-terminal extension, the unique disulfide linking residues 50 and 137. GIIA have a 7-residue C-terminal extension and seven conserved disulfide bonds, while in Group IIB, the C-terminal extension is 6 residues, and only six disulfides remained in which a universally conserved 61-95 disulfide is lacking [11]. Furthermore, a new subgroup (Lys49 PLA 2 homologues) can be created through mutation. Replacement of the 49th residue (asparagine) with lysine results in an inactive or weakly toxic $\mathrm{PLA}_{2}$. This lysine residue can also interact with other amino acids in the "calcium-binding loop" resulting in the loss of calcium-dependent catalytic activity $[17,18]$. Most svPLA ${ }_{2}$ s exist as monomers, but some exist in complexes, which mainly exhibit presynaptic neurotoxicity through combination of isoenzymes or other proteins [19].

\section{PLA $_{2}$ s Are Extensively Distributed in Snake Venom}

Mackessy [20] analyzed crude venom from the main clades of venomous snakes via SDS-PAGE and found that svPLA $2 \mathrm{~S}$ existed in almost every family (Figure 1). The highest amounts were found in Elapidae, Viperidae, and Hydrophiidae. The lowest were found in Colubridae (which is usually nonvenomous). Through the application of transcriptomics and proteomics, we gained a better understanding of venom composition and the pharmacological properties of the venom components [21]. Betzel et al. found that $\mathrm{PLA}_{2} \mathrm{~S}$ made up 32-59.8\% in Viperidae snake venom [22]. However, Bungarus fasciatus venom was found to consist of up to $71 \%$ of $\mathrm{PLA}_{2} \mathrm{~s}$ [23]. Moreover, Gutiérrez and Lomonte found that the most lethal fractions in Micrurus fulvius (family Elapidae) were two $\mathrm{PLA}_{2}$ molecules which represented $33.4 \%$ of the whole venom [24]. To date, more than 464 unique svPLA 2 have been recorded in UniProtKB database. What has been presented above indicates that $\mathrm{PLA}_{2} \mathrm{~s}$ are abundant and fatal toxins in most snake venoms.

\section{4. svPLA $s$ Have a Wide Spectrum of Pharmacological Effects}

Despite producing lysophospholipids and fatty acid proinflammatory mediators, svPLA $_{2}$ s also present a wide spectrum of pharmacological effects in victims, (i.e., neurotoxicity, myotoxicity, anticoagulant effects, cytotoxicity, cardiotoxicity, and edema, Table 1). The diverse toxic effects are tightly related to the multiple functional sites on the surface of $\mathrm{svPLA}_{2} \mathrm{~s}$ and their different binding receptors [25].

4.1. $s v P L A_{2}$ Neurotoxicity. Neurotoxic svPLA $A_{2}$ s can block neuromuscular transmission in vertebrate skeletal muscles causing acute neuromuscular weakness and paralysis resulting in respiratory depression and death [53]. Neurotoxic $\mathrm{sPLA}_{2} \mathrm{~s}$ are mainly found in the Elapidae (kraits, elapids, and coral snakes) and Viperidae (vipers and rattlesnakes). Their toxicity varies greatly among species, ranging from $1 \mu \mathrm{g} / \mathrm{kg}$ (Textilotoxin) to $380 \mu \mathrm{g} / \mathrm{kg}$ (HDP-2 from Vipera nikolskii) [53]. Previous studies indicate that there is no correlation between toxicity and $\mathrm{PLA}_{2}$ hydrolysis activity. svPLA $_{2}$ neurotoxicity affects presynaptic nerve terminals, so these compounds are commonly referred as presynaptic neurotoxins or $\beta$-neurotoxins ( $\beta$-ntxs) [54]. $\beta$-ntxs are monomers or noncovalent complexes containing $2-5$ subunits with at least one $\mathrm{PLA}_{2}$ subunit. To our knowledge, all $\beta$ ntxs hydrolyze phospholipids, especially anionic lipids (e.g., phosphatidylserine, phosphatidic acid, and phosphorylated phosphatidylinositols) which are abundant in the cytosolic leaflets of organelles and the plasma membrane of eukaryotic cells [55]. svPLA $\mathrm{A}_{2}$ s also bind to special tissue sites to achieve their neurotoxicity effects. The mechanism of svPLA $\mathrm{A}_{2}$ neurotoxicity is still under investigation.

4.2. $s v P L A_{2}$ Myotoxicity. svPLA $_{2}$ s can induce acute necrosis of skeletal muscle (myonecrosis) [56]. In the envenomation, this myonecrosis can potentially lead to permanent tissue loss or amputation [57]. svPLA 2 myotoxins are mainly found in venom from Elapidae, including sea snakes and Viperidae [58]. Depending on the venom, these svPLA $\mathrm{A}_{2} \mathrm{~s}$ can elicit local or systemic myotoxicity. Local myotoxicity is mainly elicited by viperid venom. This damage is limited to the region where the toxin is injected and is often coupled with hemorrhaging, blistering, and edema [57, 59]. Systemic myotoxicity is elicited by elapid venom (i.e., some sea snake, terrestrial elapids). This causes muscle damage and a distinct increase of creatine kinase (CK) activity in plasma and is associated with renal failure and myoglobinuria [58]. Along with sharing a highly conserved structure, svPLA 2 myotoxins are tightly associated with neurotoxins. Both achieve a similar cellular lesion through membrane perturbation, cytosolic $\mathrm{Ca}^{2+}$ homoeostasis imbalance, and cell degeneration [60]. Furthermore, some neurotoxic svPLA $\mathrm{A}_{2}$ s (e.g., notexin and crotoxin) cause acute skeletal muscle necrosis, adding to systemic toxic effects (i.e., rhabdomyolysis) [60]. 


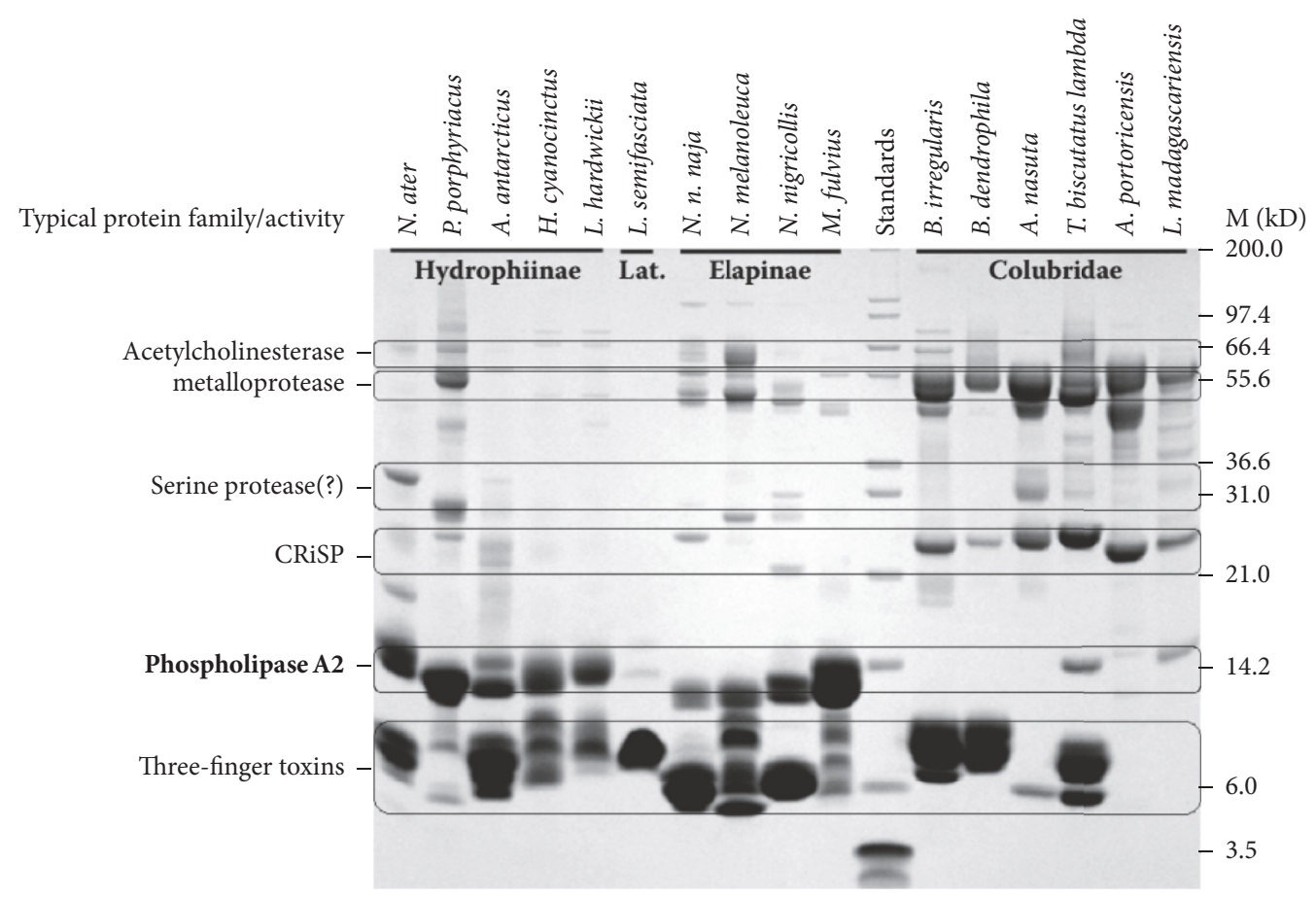

(a)

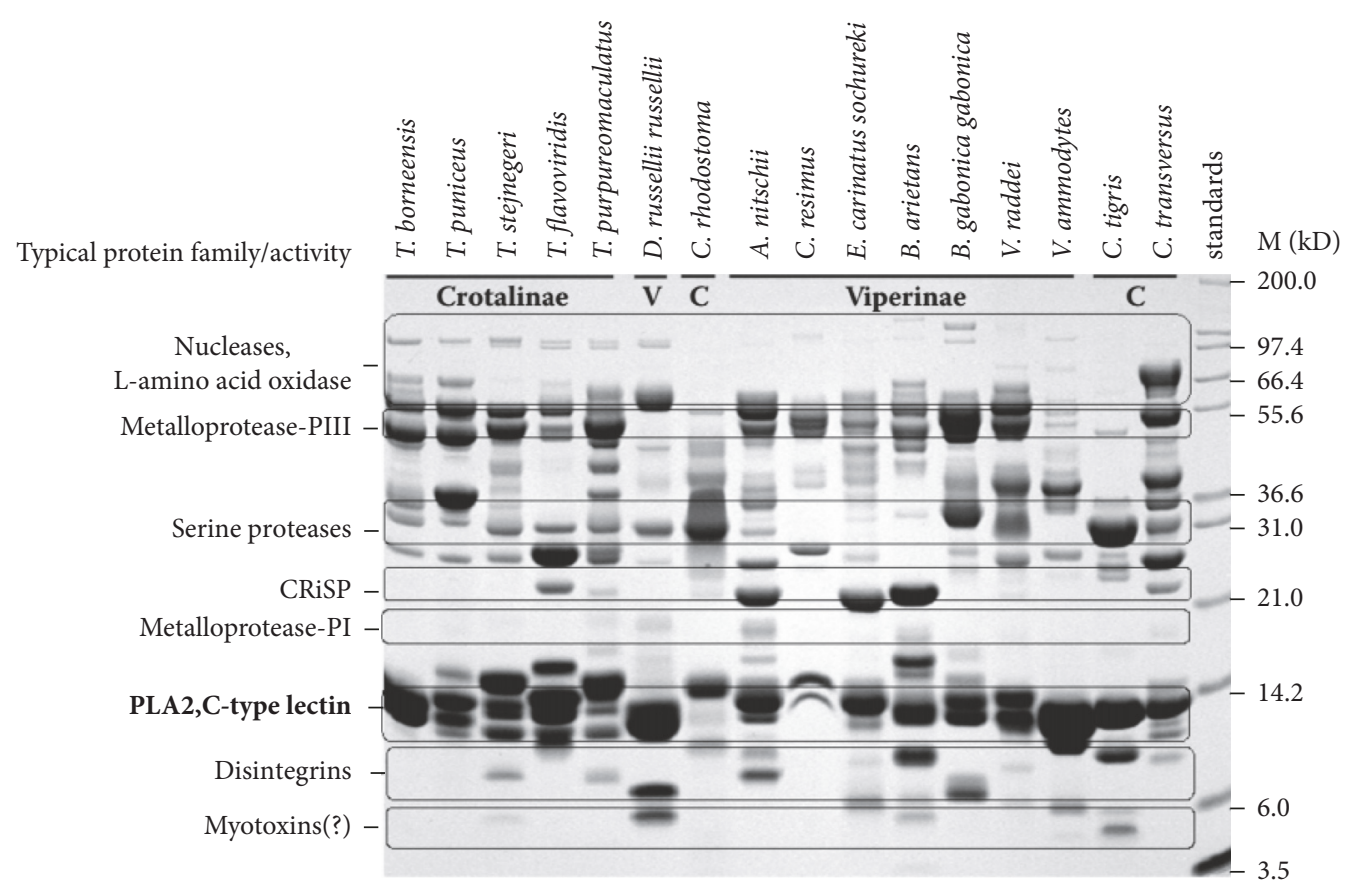

(b)

FIGURE 1: SDS-PAGE profile of major venom components in the main clades of venomous snakes (adapted from [20]). (a) Families: Elapidae, subfamilies Elapinae, Laticaudinae, Hydrophiinae, and Colubrinae. (b) Family: Viperidae, and subfamilies: Crotalinae (C) and Viperinae (V). Ovals enclose some bands that are typical of protein families, based on published mass. (?) indicates hypothetical protein family or activity.

Residue 49 in myotoxic svPLA $\mathrm{s}_{2}$ is usually associated with $\mathrm{PLA}_{2}$ enzymatic activity. Asp49-PLA $\mathrm{P}_{2}$ are generally strongly catalytic whereas Lys 49 homologues are either not catalytic or weakly catalytic. There are also other amino acid substitutions, such as Ser49, Arg49, Asn49, or Gln49
[56]. The lysophospholipids released from phospholipid that hydrolyzed by Asp49 PLA $_{2}$ usually cause skeletal muscle necrosis via direct disruption of membrane stabilization and/or indirect biophysical alteration of membrane [61]. The Lys49 PLA $_{2}$ myotoxins are devoid of catalytic activity, existing 


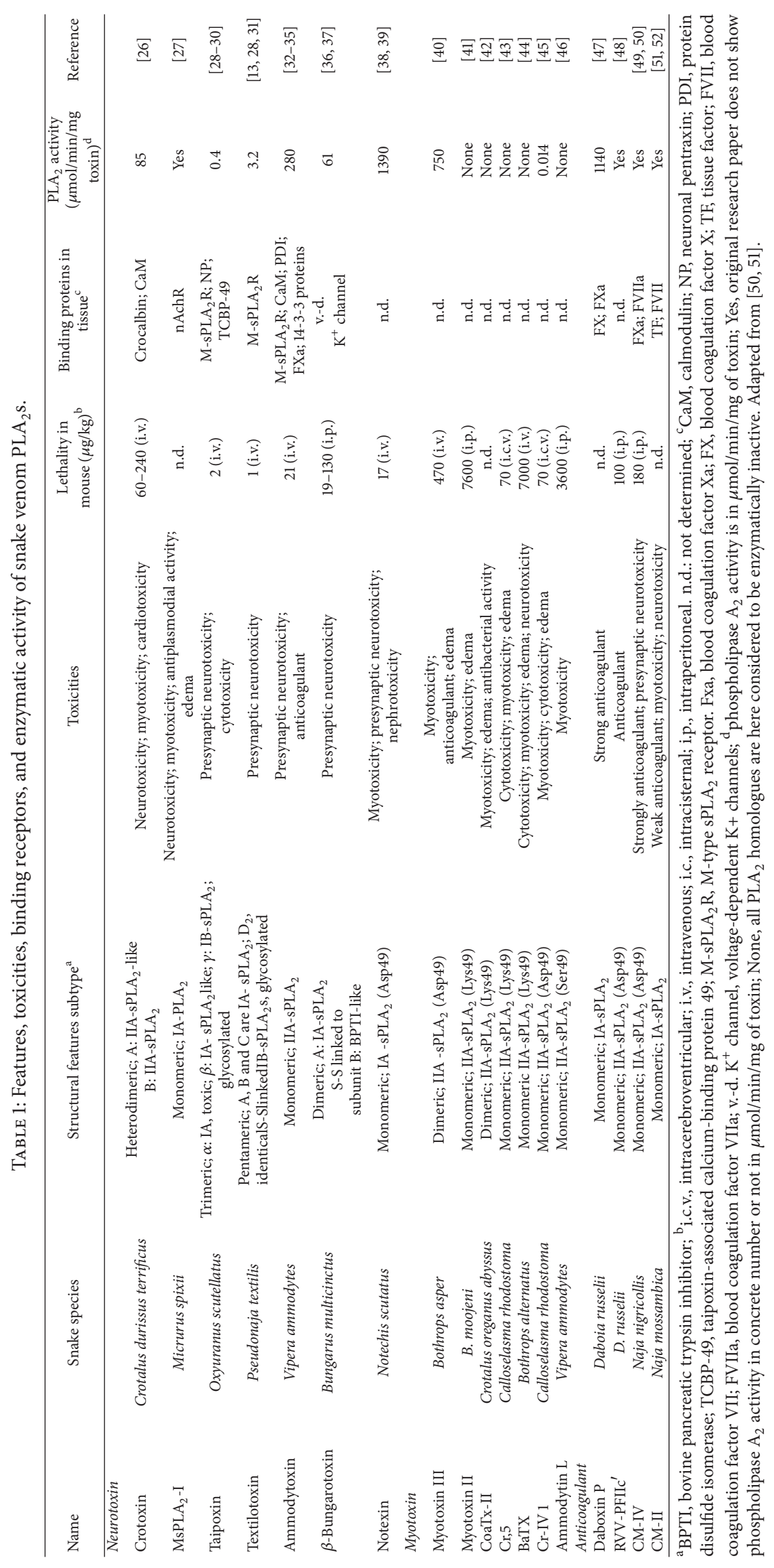


as homodimers in solution connected by noncovalent bonds [56]. Previous studies focused on the fact that amino acids composition of synthetic peptides has revealed that the $\mathrm{C}$ terminal regions of 115-129 residues, which are positively charged and full of basic, aromatic, hydrophobic residues, are the key structure in eliciting myotoxic effects [62,63]. Sitedirected mutagenesis experiments proved that Tyr117, Arg118, Tyr119, Lys122, and Phe125 also have significant impacts on myotoxicity [64].

4.3. svPLA $\mathrm{A}_{2}$ Anticoagulant Effect. The anticoagulant effect of svPLA $_{2}$ usually causes bleeding in victim/prey by inhibiting one or two steps in the blood coagulation cascade. $\mathrm{PLA}_{2} \mathrm{~S}$ can be classified as strong, weak, and nonanticoagulant based on the dose required to inhibit blood coagulation [65]. The hydrolysis of phospholipids by svPLA 2 would be the primary mechanism to account for $\mathrm{PLA}_{2}$ s' anticoagulation [66]. However, in the absence of phospholipids, some svPLA ${ }_{2} \mathrm{~S}$ could also inhibit coagulation [67]. The correlation between svPLA $_{2}$ enzymatic activity and anticoagulant effect is still unknown. Furthermore, there are other mechanisms that restrain coagulation, such as inhibition of the activation of the conversion of FX (blood coagulation factor X) to FXa (blood coagulation factor Xa) and/or prothrombin to thrombin [68].

svPLA $_{2} \mathrm{~s}$ can also induce other toxic effects such as myoglobinuria-inducing, hemolytic, and platelet aggregation initiating/inhibiting activities [49]. Their wide distribution, conserved structures, and various severe pharmacological effects suggest that svPLA ${ }_{2}$ s represent a promising target for new antivenom medicine. Indeed, there is sufficient evidence that $\mathrm{PLA}_{2}$ inhibitors (PLIs) are effective in using snake venom envenomation therapy [69].

\section{PLA Inhibitors Attenuate Morbidity and Mortality of Snakebite Envenomation}

Due to the high cost, long production period, limited categories, short storage life, and common clinical side-effects of current antivenin, scientists have attempted to create antidotes from herbal extracts, marine compounds, mammalian and snake serum, and modified chemical molecules and peptides [70]. svPLA $\mathrm{A}_{2}$ s are the ideal target and widely used for antidote screening. Indeed, both natural and synthetic svPLA $_{2}$ inhibitors are able to attenuate the morbidity and mortality of snakebite envenomation.

5.1. Natural svPLA $A_{2}$ Inhibitors from Plants, Marine Extracts, and Mammalian Serum. Medicinal plant extracts as traditional antidotes have long been used in countries where the urotherapy is unobtainable [71]. In addition, these traditional and herbal treatments are often used as adjuvant therapies along with the antivenin treatment. Most plant antitoxic agents function by neutralizing svPLA 2 's toxicity. An active glycoprotein (WSG) from Withania somnifera completely inhibits the cytotoxicity, edema, and myotoxicity of NN-Xia$\mathrm{PLA}_{2}$ isolated from Naja atra venom, but fails to neutralize the neurotoxicity [72-74]. WSG has a similar structure to the $\alpha$-chain of the PLIs derived from Australian elapid serum and was found to interact with NN-XIa-PLA 2 , but the mechanism currently remains unknown [74].

The aqueous extract of Casearia sylvestris was found to be effective against two snake venom toxins (Asp49$\mathrm{PLA}_{2}$ and Lys49-PLA 2 isolated from venom of B. moojeni, $B$. pirajai, B. neuwiedi, and $B$. jararacussu). Indeed, this plant has been found to inhibit myotoxicity, hemorrhage, anticoagulation, and edema $[75,76]$. It is also able to prevent myonecrosis initiated by two Lys49-PLA 2 toxins (PrTX-I from $B$. pirajai and BthTX-I from $B$. jararacussu venom) and neuromuscular blockages [77]. Recently research has shown that human secretory $\mathrm{PLA}_{2}$ inhibitors (e.g., quercetin, biflavonoid morelloflavone [78, 79]) isolated from plant extracts can also inhibit svPLA 2 .

Marine organisms are also a reservoir for antivenoms. Manoalide (MLD), a natural product from sponge Luffariella variabilis, can irreversibly inhibit extracellular $\mathrm{PLA}_{2}$ activity of cobra and rattlesnake venom with an $\mathrm{IC}_{50}$ value of 1.9 and $0.7 \mu \mathrm{M}$, respectively [80]. Its synthetic analogue, manoalogue (MLG), is also inhibitive to cobra PLA 2 activity with an $\mathrm{IC}_{50}$ value of $7.5 \mu \mathrm{M}$ [81].

Natural svPLA 2 inhibitors also exist in some mammalian serums. DM64 is an acidic glycoprotein isolated from serum of the opossum, Didelphis marsupialis. DM64 can completely prevent myofiber breakdown caused by myotoxins I (Asp49) and II (Lys49) of B. asper venom [82]. N-glycosylation sites (Asn46, Asn179, Asn183, and Asn379) in this antimyotoxic protein play important roles in this inhibitory action [83].

5.2. Snake Blood PLA $A_{2}$ Inhibitors. Many venomous and nonvenomous snake species are naturally resistant to the deleterious actions of snake venom components. In many cases, this is due to the presence of specific antitoxins circulating in their blood. These alexeteric factors are proteins generated in the snake's liver, with native molecular masses ranging from 75 to $180 \mathrm{kDa}$. These nonimmunoglobulin antitoxins are $\mathrm{PLA}_{2}$ inhibitors (i.e., snake blood phospholipase A2 inhibitors, sbPLIs) and are used to protect the snake from the internal or external envenomation.

sbPLIs can be produced by snakes of the Elapidae, Viperidae, Hydrophidae, Colubridae and Boidae families. These sbPLIs can be classified into three groups based on the homology of their amino acid sequence: $\alpha, \beta$ and $\gamma$ [84]. Generally, the $\alpha$ and $\gamma$ sbPLIs simultaneously occur in several snake species, while the $\beta$ sbPLIs have only been reported in three snake species. When the target $\mathrm{PLA}_{2} \mathrm{~s}$ are Lys49 homologues or Asp49 myotoxins, the sbPLIs are specifically called myotoxin inhibitor proteins (MIPs) $[85,86]$.

Since the first $\alpha$ PLI (BaMIP) was isolated from B. asper serum, 15 kinds of $\alpha$ sbPLIs have been discovered in the different venomous snake families. Previous studies have shown that BaMIP can block both myotoxins I and III (isolated from B. asper venom) [87]. The $\alpha$ PLIs, $\alpha$ TfPLI, and $\alpha$ AbsPLI also show good inhibition of the enzymatic activities of acid-PLA (isolated from Viperidae). CgMIP-II and AnMIP can inhibit the basic-PLA 2 enzymatic activities of Viperidae venom. BaMIP, BmjMIP and BjussuMIP can inhibit the enzymatic activities and toxic effects (i.e., edema, myotoxicity, and cytotoxicity) of acid/basic-PLA 2 . Furthermore, Quirós et al. 
extracted a new myotoxin inhibitor $\alpha$ PLI from $A$. nummifer serum (AnMIP) and found that this protein, at a ratio of $1: 1$, could decrease $67 \%$ of the A. nummifer myotoxin II and $93 \%$ of the B. asper myotoxin I [85].

Currently four kinds of $\beta$ sbPLIs have been found in three snake species. $\beta$ PLI specifically inhibits the basic$\mathrm{PLA}_{2}$ enzymatic activities of Viperidae. The first $\beta$ sbPLI was purified from $G$. brevicaudus as a homotrimer and is specific for basic-PLA $\mathrm{A}_{2}$ from homologous venoms and forms a stable $\mathrm{PLA}_{2}-\beta$ sbPLI complex at a molar ratio of $1: 1$ [88].

Twenty-three types of $\gamma$ sbPLIs have been found in venomous and nonvenomous species. $\gamma$ PLI from Elapidae and other nonvenomous snakes can inhibit $\mathrm{PLA}_{2}$ activity in a range of different snake venoms. We recently reported a novel $\gamma$ PLI isolated from the serum of Sinonatrix annularis, named $\gamma$ saPLI, that showed a strong inhibition of lecithin degradation elicited by $D$. acutus venom $\mathrm{PLA}_{2} \mathrm{~s}$ in an in vitro study [89]. The $\gamma$ saPLI was also effective in the inhibition of hemorrhagic toxicities elicited by D. acutus, N. atra, and A. halys venom [90].

5.3. Poly or Monoclonal Antibodies of svPLA $A_{2}$ Are Effective in Neutralizing Snake Venom. Unlike the common antivenins of venom proteome, Garcia Denegri et al. developed a polyantibody using a nontoxic $\mathrm{PLA}_{2}$ (BaSpII RP4) from Bothrops alternatus as antigen [91]. This antibody showed a specific and sensitive inhibition of the venom $\mathrm{PLA}_{2}$ s' enzymatic activity. Furthermore, the myotoxicity and mortality of the crude venom were significantly reduced in the presence of anti$\mathrm{PLA}_{2}$ IgG. When treated with a high dose of $2 \times \mathrm{LD}_{50}$, equivalent to $112 \mu \mathrm{g}$ of $B$. alternatus venom and $2.62 \mathrm{mg}$ of IgG, all of the test animals survived after $48 \mathrm{~h}$. In contrast, the control group (112 $\mu \mathrm{g}$ venom preincubated with PBS) died within 4 hours. $5.25 \mathrm{mg}$ of IgG treated animals could even endure as high as 4 times the $\mathrm{LD}_{50}$ dose of venom $(224 \mu \mathrm{g})$, with half of the treated group remaining alive at the end of $48 \mathrm{~h}$. In contrast, the control group ( $224 \mu \mathrm{g}$ venom preincubated with PBS) died shortly within 90 mins.

Rodriguez et al. also produced a IgG against crotoxin (a basic $\mathrm{PLA}_{2}$ ), the principle toxin of $C$. durissus terrificus (C.d.t.) with high myotoxic and neurotoxic activities. Mice preincubated with the anticrotoxin IgG showed low mortality after 24 and $48 \mathrm{~h}$ of inoculation (at $4 \mu \mathrm{g}$ C.d.t. venom/test animal). The investigation showed that the IgGs of anti-PLA $\mathrm{P}_{2}$ were more effective than anticrotalic serum at neutralizing lethal activity [92]. Additionally, the anti$\mathrm{PLA}_{2}$ IgGs raised via immunization with $\mathrm{P} 9 \mathrm{a}$ or P10a, two types of less toxic Cdt-PLA2s, cross-reacted with all the isoforms of $\mathrm{PLA}_{2} \mathrm{~s}$ in the C.d.t. venom [93]. Although these antitoxic effects were only tested with their original venoms, the wide cross-reaction of these anti-PLA $A_{2}$ IgGs with other svPLA $_{2}$ s suggested that these compounds could likely also be used to neutralize other snake venoms. In other words, the improved neutralization activity of these anti-svPLA $\mathrm{A}_{2}$ IgGs indicates svPLA $\mathrm{P}_{2} \mathrm{~s}$ are a promising target for broad-spectrum antivenom drug development.

5.4. Artificial Inhibitor of Mammal PLA $A_{2}$ Exhibits Effective Antivenom Activity. Varespladib (LY315920) was designed as an inhibitor of the IIa, V, and X isoforms of the mammalian secretory phospholipase $\mathrm{A}_{2}\left(\mathrm{sPLA}_{2}\right)$. This compound acts as an anti-inflammatory agent by disrupting the first step of the arachidonic acid pathway of inflammation. From 2006 to 2012, varespladib was under active investigation by Anthera Pharmaceuticals for using as a potential therapy for several inflammatory diseases, including acute coronary syndrome and acute chest syndrome [94, 95]. Thought to be an effective antiatherosclerotic agent, varespladib showed promising therapeutic effects in reducing plasma sPLA 2 and low-density lipoprotein (LDL) [96].

Varespladib has recently been repurposed as an effective broad-spectrum svPLA 2 inhibitor and used for treatment of snakebite envenomation. Varespladib and its orally bioavailable prodrug methyl-varespladib (LY333013) showed strong inhibitory ability of 28 kinds of svPLA ${ }_{2}$ s from six continents. Indeed, the $\mathrm{IC}_{50}$ values ranged from nano- to picomolars in an in vitro experiment [97]. Additionally, the compound elicited surprising effects with eastern coral snake (Micrurus fulvius) venom, which was considered to have the highest sPLA $_{2}$ activity and most intense hemo- and neurotoxic effects. Pretreatment with $0.1 \mathrm{mg}$ of varespladib prolonged survival in mice at 4 times the $\mathrm{LD}_{50}$ dose of eastern coral snake venom over the course of $8 \mathrm{~h}$. All the negative control mice died at an average of $63 \mathrm{~min}$, whereas the varespladib treatment group survived for an average of $1140 \mathrm{~min}$. Varespladib also showed promising in vivo protection in Vipera berus envenomed mice. Mice treated with a subcutaneous injection of a $100 \%$ lethal dose of venom and varespladib survived for more than $24 \mathrm{~h}$ [97]. These findings are solid evidence of svPLA $_{2}$ being the target for a broad-spectrum antivenom.

\section{Conclusions}

svPLA $_{2} \mathrm{~s}$ are widely distributed in snake venoms. A svPLA could elicit one or more pharmacological effects (e.g., neurotoxicity, myotoxicity, anticoagulant, and edema). Furthermore, svPLA $A_{2}$ can interact with other svPLA ${ }_{2}$ s (e.g., two different svPLA 2 , the "Asp" and "Lys" myotoxins from Bothrops asper, have been shown to synergistically enhance myonecrosis in in vitro and in vivo studies [98]) or other venom components (e.g., taicatoxin, a $\mathrm{Ca}^{2+}$ channel inhibitor composed of an $\alpha$-neurotoxin-like peptide, a neurotoxic phospholipase $\mathrm{A}_{2}$, and a serine protease inhibitor, connected by noncovalent bonds [99]).

A variety of $\mathrm{PLA}_{2}$ inhibitors were discovered or synthesized in the past few decades. Most inhibitors extracted from medical plants, marine animals, and mammalian serum specially inhibit svPLA 2 toxicity. sbPLIs are natural, endogenous protective components against snake venom, among which the $\gamma$ PLI were commonly inhibitive to different category of venoms [100]. Anti-PLA 2 antibodies could specifically inactivate enzymatic activity and toxicity, both with the original venom and other svPLA 2 s [93]. Indeed, some of these compounds could function even better than the antivenin that is currently clinically applied [92]. A synthetic human $\mathrm{SPA}_{2}$ inhibitor varespladib was found to possess the ability to neutralize a variety of snake venoms 
worldwide, with significant prolongation of survival time on rats that were inoculated with varespladib simultaneously or following exposure [97]. In conclusion, the anti-PLA 2 drugs are promising antidotes for a broad-spectrum of snake venoms and other animal toxins and could also be effective in prevention of inflammatory reactions (i.e., systemic toxicological syndromes).

\section{Conflicts of Interest}

The authors confirm that this article content has no conflicts of interest.

\section{Authors' Contributions}

Huixiang Xiao and Hong Pan contributed equally to this work and are considered as co-first authors.

\section{Acknowledgments}

The authors are grateful for the support of the National Natural Science Foundation of China (no. 31260209 and no. 31460227); Natural Science Foundation of Jiangxi Province (20171BAB204015); and Cultivating Foundation of Young Scientists of Jiangxi Province (20171BCB23018).

\section{References}

[1] D. A. Warrell, "Snake bite," The Lancet, vol. 375, no. 9708, pp. 7788, 2010.

[2] J.-P. Chippaux, "Snake-bites: appraisal of the global situation," Bulletin of the World Health Organization, vol. 76, no. 5, pp. 515$524,1998$.

[3] Editorial, "Snake bite-the neglected tropical disease," Lancet, vol. 386, no. 9999, pp. 1110, 2015.

[4] J. M. Gutiérrez, R. D. G. Theakston, and D. A. Warrell, "Confronting the neglected problem of snake bite envenoming: the need for a global partnership," PLoS Medicine, vol. 3, no. 6, pp. 0727-0731, 2006.

[5] H. A. De Silva, N. M. Ryan, and H. J. De Silva, "Adverse reactions to snake antivenom, and their prevention and treatment," British Journal of Clinical Pharmacology, vol. 81, no. 3, pp. 446452, 2016.

[6] J. M. Gutiérrez, D. Williams, H. W. Fan, and D. A. Warrell, "Snakebite envenoming from a global perspective: towards an integrated approach," Toxicon, vol. 56, no. 7, pp. 1223-1235, 2010.

[7] Q. Schiermeier, "Africa braced for snakebite crisis," Nature, vol. 525, no. 7569, p. 299, 2015.

[8] D. L. Scott, "Phospholipase $A_{2}$ structure and catalytic properties," in In Venom Phospholipase $A_{2}$ Enzymes: Structure, Function, and Mechanism, R. M. Kini, Ed., pp. 97-128, John Wiley, Chichester, UK, 1997.

[9] E. A. Dennis, J. Cao, Y.-H. Hsu, V. Magrioti, and G. Kokotos, "Phospholipase $\mathrm{A}_{2}$ enzymes: physical structure, biological function, disease implication, chemical inhibition, and therapeutic intervention," Chemical Reviews, vol. 111, no. 10, pp. 6130-6185, 2011.

[10] R. H. Schaloske and E. A. Dennis, "The phospholipase $\mathrm{A}_{2}$ superfamily and its group numbering system," Biochimica et Biophysica Acta (BBA) - Molecular and Cell Biology of Lipids, vol. 1761, no. 11, pp. 1246-1259, 2006.
[11] D. A. Six and E. A. Dennis, "The expanding superfamily of phospholipase A2 enzymes: classification and characterization," Biochimica et Biophysica Acta (BBA) - Molecular and Cell Biology of Lipids, vol. 1488, no. 1-2, pp. 1-19, 2000.

[12] J. Fohlman, P. Lind, and D. Eaker, “Taipoxin, an extremely potent presynaptic snake venom neurotoxin Elucidation of the primary structure of the acidic carbohydrate-containing taipoxin-subunit, a prophospholipase homolog," FEBS Letters, vol. 84, no. 2, pp. 367-371, 1977.

[13] J. A. Pearson, M. I. Tyler, K. V. Retson, and M. E. H. Howden, "Studies on the subunit structure of textilotoxin, a potent presynaptic neurotoxin from the venom of the Australian common brown snake (Pseudonaja textilis). 3. The complete amino-acid sequences of all the subunits," Biochimica et Biophysica Acta (BBA) - Protein Structure and Molecular Enzymology, vol. 1161, no. 2-3, pp. 223-229, 1993.

[14] B. R. Francis, N. Jorge Da Silva Jr., C. Seebart, L. L. Casais E Silva, J. J. Schmidt, and I. I. Kaiser, "Toxins isolated from the venom of the Brazilian coral snake (Micrurus frontalis frontalis) include hemorrhagic type phospholipases A2 and postsynaptic neurotoxins," Toxicon, vol. 35, no. 8, pp. 1193-1203, 1997.

[15] R. C. De Paula, H. C. Castro, C. R. Rodrigues, P. A. Melo, and A. L. Fuly, "Structural and pharmacological features of phospholipases $\mathrm{A}_{2}$ from snake venoms," Protein and Peptide Letters, vol. 16, no. 8, pp. 899-907, 2009.

[16] S. P. Mackessy, "Snake Venom Phospholipase $A_{2}$ Enzymes," in Handbook of Venoms and Toxins of Reptiles, S. P. Mackessy, Ed., pp. 174-195, Taylor and Francis, Boca Raton, Fla, USA, 2010.

[17] T. Petan, I. Križaj, and J. Pungerčar, "Restoration of enzymatic activity in a Ser- 49 phospholipase $\mathrm{A}_{2}$ homologue decreases its $\mathrm{Ca}^{2+}$-independent membrane-damaging activity and increases its toxicity," Biochemistry, vol. 46, no. 44, pp. 12795-12809, 2007.

[18] R. J. Ward, L. Chioato, A. H. C. De Oliveira, R. Ruller, and J. M. Sá, "Active-site mutagenesis of a Lys49-phospholipase $\mathrm{A}_{2}$ : Biological and membrane-disrupting activities in the absence of catalysis," Biochemical Journal, vol. 362, no. 1, pp. 89-96, 2002.

[19] C. Bon, "Multicomponent neurotoxic phospholipases $\mathrm{A}_{2}$," in Venom Phospholipase $A_{2}$ Enzymes: Structure, Function, and Mechanism, R. M. Kini, Ed., pp. 269-285, John Wiley, Chichester, UK, 1997.

[20] S. P. Mackessy, "The field of reptile toxinology snakes, lizards, and their venoms," in In Handbook of Venoms and Toxins of Reptiles, S. P. Mackessy, Ed., pp. 3-19, Taylor and Francis, Boca Raton, Fla, USA, 2010.

[21] J. J. Calvete, "Proteomics in venom research: a focus on $\mathrm{PLA}_{2}$ molecules," Acta Chimica Slovenica, vol. 58, no. 4, pp. 629-637, 2011.

[22] D. Georgieva, R. K. Arni, and C. Betzel, "Proteome analysis of snake venom toxins: pharmacological insights," Expert Review of Proteomics, vol. 5, no. 6, pp. 787-797, 2008.

[23] R. H. Ziganshin, S. I. Kovalchuk, G. P. Arapidi et al., "Quantitative proteomic analysis of vietnamese krait venoms: neurotoxins are the major components in bungarus multicinctus and phospholipases $\mathrm{A}_{2}$ in bungarus fasciatus," Toxicon, vol. 107, pp. 197-209, 2015.

[24] J. M. Gutiérrez and B. Lomonte, "Phospholipases $\mathrm{A}_{2}$ : unveiling the secrets of a functionally versatile group of snake venom toxins," Toxicon, vol. 62, pp. 27-39, 2013.

[25] R. M. Kini, "Excitement ahead: structure, function and mechanism of snake venom phospholipase $\mathrm{A}_{2}$ enzymes," Toxicon, vol. 42, no. 8, pp. 827-840, 2003. 
[26] S. C. Sampaio, S. Hyslop, M. R. M. Fontes et al., "Crotoxin: novel activities for a classic $\beta$-neurotoxin," Toxicon, vol. 55 , no. 6, pp. 1045-1060, 2010.

[27] A. L. C. Terra, L. S. Moreira-Dill, R. Simões-Silva et al., "Biological characterization of the amazon coral micrurus spixii snake venom: isolation of a new neurotoxic phospholipase $\mathrm{A}_{2}$," Toxicon, vol. 103, pp. 1-11, 2015.

[28] G. Lambeau, P. Ancian, J. Barhanin, and M. Lazdunski, "Cloning and expression of a membrane receptor for secretory phospholipases $\mathrm{A}_{2}$," The Journal of Biological Chemistry, vol. 269, no. 3, pp. 1575-1578, 1994.

[29] G. Lambeau, A. Schmid-Alliana, M. Lazdunski, and J. Barhanin, "Identification and purification of a very high affinity binding protein for toxic phospholipases $\mathrm{A}_{2}$ in skeletal muscle," The Journal of Biological Chemistry, vol. 265, no. 16, pp. 9526-9532, 1990.

[30] B. V. Lipps, "Isolation of subunits, $\alpha, \beta$ and $\gamma$ of the complex taipoxin from the venom of Australian taipan snake (Oxyuranus s. scutellatus): characterization of $\beta$ taipoxin as a potent mitogen," Toxicon, vol. 38, no. 12, pp. 1845-1854, 2000.

[31] A. Coulter, R. Harris, A. Broad et al., "The isolation and some properties of the major neurotoxic component from the venom of the common or Eastern Australian brown snake (Pseudonaja textilis)," Toxicon, vol. 21, no. 3, pp. 81-84, 1983.

[32] G. Faure, V. T. Gowda, and R. C. Maroun, "Characterization of a human coagulation factor Xa-binding site on Viperidae snake venom phospholipases $A_{2}$ by affinity binding studies and molecular bioinformatics," BMC Structural Biology, vol. 7, article no. 82, 2007.

[33] J. Šribar, A. Čopič, A. Pariš et al., "A high affinity acceptor for phospholipase $\mathrm{A}_{2}$ with neurotoxic activity is a calmodulin," The Journal of Biological Chemistry, vol. 276, no. 16, pp. 12493-12496, 2001.

[34] J. Šribar, N. E. Sherman, P. Prijatelj et al., "The neurotoxic phospholipase $\mathrm{A}_{2}$ associates, through a non-phosphorylated binding motif, with 14-3-3 protein $\gamma$ and $\varepsilon$ isoforms," Biochemical and Biophysical Research Communications, vol. 302, no. 4, pp. 691696, 2003.

[35] N. Vardjan, N. E. Sherman, J. Pungerčar, J. W. Fox, F. Gubenšek, and I. Križaj, "High-molecular-mass receptors for ammodytoxin in pig are tissue-specific isoforms of M-type phospholipase $\mathrm{A}_{2}$ receptor," Biochemical and Biophysical Research Communications, vol. 289, no. 1, pp. 143-149, 2001.

[36] K. Kondo, H. Toda, K. Narita, and C.-Y. Lee, "Amino acid sequences of three $\beta$-bungarotoxins ( $\beta 3$-, $\beta 4$-, and $\beta 5$-bungarotoxins) from Bungarus multicinctus Venom. amino acid substitutions in the A chains," The Journal of Biochemistry, vol. 91, no. 5, pp. 1531-1548, 1982.

[37] M. J. Sutcliffe, C. M. Dobson, and R. E. Oswald, "Solution structure of neuronal bungarotoxin determined by two-dimensional NMR spectroscopy: calculation of tertiary structure using systematic homologous model building, dynamical simulated annealing, and restrained molecular dynamics," Biochemistry, vol. 31, no. 11, pp. 2962-2970, 1992.

[38] J. Halpert and D. Eaker, "Amino acid sequence of a presynaptic neurotoxin from the venom of Notechis scutatus scutatus (Australian tiger snake)," The Journal of Biological Chemistry, vol. 250, no. 17, pp. 6990-6997, 1975.

[39] B. Westerlund, P. Nordlund, U. Uhlin, D. Eaker, and H. Eklund, "The three-dimensional structure of notexin, a presynaptic neurotoxic phospholipase $\mathrm{A}_{2}$ at 2.0 Å resolution," FEBS Letters, vol. 301, no. 2, pp. 159-164, 1992.
[40] I. I. Kaiser, J. M. Gutierrez, D. Plummer, S. D. Aird, and G. V. Odell, "The amino acid sequence of a myotoxic phospholipase from the venom of Bothrops asper," Archives of Biochemistry and Biophysics, vol. 278, no. 2, pp. 319-325, 1990.

[41] A. M. Soares, V. M. Rodrigues, M. I. Homsi-Brandeburgo et al., "A rapid procedure for the isolation of the LYS-49 myotoxin II from bothrops moojeni (caissaca) venom: biochemical characterization, crystallization, myotoxic and edematogenic activity," Toxicon, vol. 36, no. 3, pp. 503-514, 1998.

[42] J. R. Almeida, M. Lancellotti, A. M. Soares et al., "CoaTx-II, a new dimeric Lys49 phospholipase $\mathrm{A}_{2}$ from Crotalus oreganus abyssus snake venom with bactericidal potential: Insights into its structure and biological roles," Toxicon, vol. 120, pp. 147-158, 2016.

[43] V. L. Bonfim, L. A. Ponce-Soto, J. C. Novello, and S. Marangoni, "Structural and functional properties of Cr 5, a new Lys49 phospholipase $\mathrm{A}_{2}$ homologue isolated from the venom of the snake Calloselasma rhodostoma," The Protein Journal, vol. 25, no. 7-8, pp. 492-502, 2006.

[44] L. A. Ponce-Soto, B. Lomonte, J. M. Gutiérrez, L. RodriguesSimioni, J. C. Novello, and S. Marangoni, "Structural and functional properties of BaTX, a new Lys49 phospholipase $\mathrm{A}_{2}$ homologue isolated from the venom of the snake Bothrops alternatus," Biochimica et Biophysica Acta (BBA) - General Subjects, vol. 1770, no. 4, pp. 585-593, 2007.

[45] V. L. Bonfim, L. A. Ponce-Soto, D. Martins de Souza et al., "Structural and functional characterization of myotoxin, CrIV 1, a phospholipase $A_{2}$ D49 from the venom of the snake Calloselasma rhodostoma," Biologicals, vol. 36, no. 3, pp. 168176, 2008.

[46] I. KRIŽAJ, A. L. BIEBER, A. RITONJA, and F. GUBENšEK, "The primary structure of ammodytin L, a myotoxic phospholipase $\mathrm{A}_{2}$ homologue from Vipera ammodytes venom," European Journal of Biochemistry, vol. 202, no. 3, pp. 1165-1168, 1991.

[47] M. Sharma, J. K. Iyer, N. Shih et al., "Daboxin p, a major phospholipase $\mathrm{A}_{2}$ enzyme from the indian daboia russelii russelii venom targets factor $\mathrm{x}$ and factor $\mathrm{xa}$ for its anticoagulant activity," PLoS ONE, vol. 11, no. 4, Article ID e0153770, 2016.

[48] A. K. Chakraborty, R. H. Hall, and A. C. Ghose, "Purification and characterization of a potent hemolytic toxin with phospholipase $\mathrm{A}_{2}$ activity from the venom of Indian Russell's viper," Molecular and Cellular Biochemistry, vol. 237, no. 1-2, pp. 95-102, 2002.

[49] R. T. Kerns, R. M. Kini, S. Stefansson, and H. J. Evans, “Targeting of venom phospholipases: The strongly anticoagulant phospholipase $A_{2}$ from Naja nigricollis venom binds to coagulation factor Xa to inhibit the prothrombinase complex," Archives of Biochemistry and Biophysics, vol. 369, no. 1, pp. 107-113, 1999.

[50] R. M. Kini, "Structure-function relationships and mechanism of anticoagulant phospholipase $\mathrm{A}_{2}$ enzymes from snake venoms," Toxicon, vol. 45, no. 8, pp. 1147-1161, 2005.

[51] F. J. Joubert, "Naja mossambica mossambica venom Purification, some properties and the amino acid sequences of three phospholipases A (CM-I, CM-II and CM-III)," BBA - Protein Structure, vol. 493, no. 1, pp. 216-227, 1977.

[52] W. W. Lin, P. L. Chang, C. Y. Lee, and F. J. Joubert, "Pharmacological study on phospholipases $\mathrm{A}_{2}$ isolated from Naja mossambica mossambica venom," Proceedings of the National Science Council, Republic of China, Part B, Life Sciences, vol. 11, no. 2, pp. 155-163, 1987.

[53] U. K. Ranawaka, D. G. Lalloo, H. J. de Silva, and J. White, "Neurotoxicity in snakebite-the limits of our knowledge," 
PLOS Neglected Tropical Diseases, vol. 7, no. 10, Article ID e2302, 2013.

[54] J. Pungerčar and I. Križaj, "Understanding the molecular mechanism underlying the presynaptic toxicity of secreted phospholipases A," Toxicon, vol. 50, no. 7, pp. 871-892, 2007.

[55] T. Petan, I. Križaj, M. H. Gelb, and J. Pungerčar, "Ammodytoxins, potent presynaptic neurotoxins, are also highly efficient phospholipase $\mathrm{A}_{2}$ enzymes," Biochemistry, vol. 44, no. 37, pp. 12535-12545, 2005.

[56] B. Lomonte and J. Rangel, "Snake venom Lys49 myotoxins: from phospholipases $\mathrm{A}_{2}$ to non-enzymatic membrane disruptors," Toxicon, vol. 60, no. 4, pp. 520-530, 2012.

[57] R. Otero, J. Gutiérrez, M. Beatriz Mesa et al., "Complications of Bothrops, Porthidium, and Bothriechis snakebites in Colombia. A clinical and epidemiological study of 39 cases attended in a university hospital," Toxicon, vol. 40, no. 8, pp. 1107-1114, 2002.

[58] J. M. Gutiérrez and C. L. Ownby, "Skeletal muscle degeneration induced by venom phospholipases $\mathrm{A}_{2}$ : insights into the mechanisms of local and systemic myotoxicity," Toxicon, vol. 42, no. 8 , pp. 915-931, 2003.

[59] R. Milani Júnior, M. T. Jorge, F. P. Ferraz de Campos et al., "Snake bites by the jararacuçu (Bothrops jararacussu): clinicopathological studies of 29 proven cases in São Paulo State, Brazil," QJM: An International Journal of Medicine, vol. 90, no. 5, pp. 323-334, 1997.

[60] C. Montecucco, J. M. Gutiérrez, and B. Lomonte, "Cellular pathology induced by snake venom phospholipase $\mathrm{A}_{2}$ myotoxins and neurotoxins: common aspects of their mechanisms of action," Cellular and Molecular Life Sciences, vol. 65, no. 18, pp. 2897-2912, 2008.

[61] B. Lomonte and J. M. Gutierrez, "Phospholipases $A_{2}$ from viperidae snake venoms: how do they induce skeletal muscle damage?" Acta Chimica Slovenica, vol. 58, no. 4, pp. 647-659, 2011.

[62] B. Lomonte, E. Moreno, A. Tarkowski, L. Å. Hanson, and M. Maccarana, "Neutralizing interaction between heparins and myotoxin II, a lysine 49 phospholipase $\mathrm{A}_{2}$ from Bothrops asper snake venom: identification of a heparin-binding and cytolytic toxin region by the use of synthetic peptides and molecular modeling," The Journal of Biological Chemistry, vol. 269, no. 47, pp. 29867-29873, 1994.

[63] C. E. Núez, Y. Angulo, and B. Lomonte, "Identification of the myotoxic site of the Lys49 phospholipase $\mathrm{A}_{2}$ from Agkistrodon piscivorus piscivorus snake venom: Synthetic Cterminal peptides from Lys49, but not from Asp49 myotoxins, exert membrane-damaging activities," Toxicon, vol. 39, no. 10, pp. 1587-1594, 2001.

[64] L. Chioato, E. A. Aragão, T. Lopes Ferreira, A. Ivo de Medeiros, L. H. Faccioli, and R. J. Ward, "Mapping of the structural determinants of artificial and biological membrane damaging activities of a Lys49 phospholipase $\mathrm{A}_{2}$ by scanning alanine mutagenesis," Biochimica et Biophysica Acta (BBA) - Biomembranes, vol. 1768, no. 5, pp. 1247-1257, 2007.

[65] H. M. Verheij, M.-C. Boffa, C. Rothen, M. Bryckaert, R. Verger, and G. H. de Haas, "Correlation of Enzymatic Activity and Anticoagulant Properties of Phospholipase A2," European Journal of Biochemistry, vol. 112, no. 1, pp. 25-32, 1980.

[66] R. M. Kini, "Anticoagulant proteins from snake venoms: Structure, function and mechanism," Biochemical Journal, vol. 397, no. 3, pp. 377-387, 2006.

[67] D. Saikia, R. Thakur, and A. K. Mukherjee, "An acidic phospholipase A2 (RVVA-PLA2-I) purified from Daboia russelli venom exerts its anticoagulant activity by enzymatic hydrolysis of plasma phospholipids and by non-enzymatic inhibition of factor $\mathrm{Xa}$ in a phospholipids/Ca ${ }^{2+}$ independent manner," Toxicon, vol. 57, no. 6, pp. 841-850, 2011.

[68] S. Stefansson, R. M. Kini, and H. J. Evans, "The basic phospholipase $\mathrm{A}^{2}$ from Naja nigricollis venom inhibits the prothrombinase complex by a novel nonenzymatic mechanism," Biochemistry, vol. 29, no. 33, pp. 7742-7746, 1990.

[69] R. P. Samy, P. Gopalakrishnakone, and V. T. Chow, “Therapeutic application of natural inhibitors against snake venom phospholipase A2," Bioinformation, vol. 8, no. 1, pp. 48-57, 2012.

[70] S. Marcussi, C. D. Sant'Ana, C. Z. Oliveira et al., "Snake venom phospholipase $\mathrm{A}^{2}$ inhibitors: Medicinal chemistry and therapeutic potential," Current Topics in Medicinal Chemistry, vol. 7, no. 8, pp. 743-756, 2007.

[71] A. M. Soares, F. K. Ticli, S. Marcussi et al., "Medicinal plants with inhibitory properties against snake venoms," Current Medicinal Chemistry, vol. 12, no. 22, pp. 2625-2641, 2005.

[72] M. Deepa and T. Veerabasappa Gowda, "Purification and characterization of a glycoprotein inhibitor of toxic phospholipase from Withania somnifera," Archives of Biochemistry and Biophysics, vol. 408, no. 1, pp. 42-50, 2002.

[73] L. Mishra, B. B. Singh, and S. Dagenais, "Scientific basis for the therapeutic use of Withania somnifera (ashwagandha): a review," Alternative Medicine Review, vol. 5, no. 4, pp. 334-346, 2000.

[74] D. K. Machiah and T. V. Gowda, "Purification of a postsynaptic neurotoxic phospholipase $A_{2}$ from Naja naja venom and its inhibition by a glycoprotein from Withania somnifera," Biochimie, vol. 88, no. 6, pp. 701-710, 2006.

[75] M. H. Borges, A. M. Soares, V. M. Rodrigues et al., "Effects of aqueous extract of Casearia sylvestris (Flacourtiaceae) on actions of snake and bee venoms and on activity of phospholipases $\mathrm{A}_{2}$," Comparative Biochemistry and Physiology - B Biochemistry and Molecular Biology, vol. 127, no. 1, pp. 21-30, 2000.

[76] M. H. Borges, A. M. Soares, V. M. Rodrigues et al., "Neutralization of proteases from Bothrops snake venoms by the aqueous extract from Casearia sylvestris (Flacourtiaceae)," Toxicon, vol. 39, no. 12, pp. 1863-1869, 2001.

[77] W. L. G. Cavalcante, T. O. Campos, M. Dal Pai-Silva et al., "Neutralization of snake venom phospholipase $\mathrm{A}_{2}$ toxins by aqueous extract of Casearia sylvestris (Flacourtiaceae) in mouse neuromuscular preparation," Journal of Ethnopharmacology, vol. 112, no. 3, pp. 490-497, 2007.

[78] J. A. Pereañez, A. C. Patiño, V. Núñez, and E. Osorio, “The biflavonoid morelloflavone inhibits the enzymatic and biological activities of a snake venom phospholipase $\mathrm{A}_{2}$," ChemicoBiological Interactions, vol. 220, pp. 94-101, 2014.

[79] C. A. Cotrim, S. C. B. De Oliveira, E. B. S. Diz Filho et al., "Quercetin as an inhibitor of snake venom secretory phospholipase $\mathrm{A}_{2}$," Chemico-Biological Interactions, vol. 189, no. 1-2, pp. 9-16, 2011.

[80] C. F. Bennett, S. Mong, M. A. Clarke, L. I. Kruse, and S. T. Crooke, "Differential effects of manoalide on secreted and intracellular phospholipases," Biochemical Pharmacology, vol. 36, no. 5, pp. 733-740, 1987.

[81] L. J. Reynolds, B. P. Morgan, G. A. Hite, E. D. Mihelich, and E. A. Dennis, "Phospholipase $\mathrm{A}_{2}$ inhibition and modification by manoalogue," Journal of the American Chemical Society, vol. 110, no. 15 , pp. 5172-5177, 1988. 
[82] S. L. G. Rocha, B. Lomonte, A. G. C. Neves-Ferreira et al., "Functional analysis of DM64, an antimyotoxic protein with immunoglobulin-like structure from Didelphis marsupialis serum," European Journal of Biochemistry, vol. 269, no. 24, pp. 6052-6062, 2002.

[83] I. R. León, A. G. da Costa Neves-Ferreira, S. L. G. da Rocha, M. R. de Oliveira Trugilho, J. Perales, and R. H. Valente, "Using mass spectrometry to explore the neglected glycan moieties of the antiophidic proteins DM43 and DM64," Proteomics, vol. 12, no. 17, pp. 2753-2765, 2012.

[84] S. Lizano, G. Domont, and J. Perales, "Natural phospholipase $\mathrm{A}_{2}$ myotoxin inhibitor proteins from snakes, mammals and plants," Toxicon, vol. 42, no. 8, pp. 963-977, 2003.

[85] S. Quirós, A. Alape-Girón, Y. Angulo, and B. Lomonte, "Isolation, characterization and molecular cloning of AnMIP, a new $\alpha$-type phospholipase $\mathrm{A}_{2}$ myotoxin inhibitor from the plasma of the snake Atropoides nummifer (Viperidae: Crotalinae)," Comparative Biochemistry and Physiology - B Biochemistry and Molecular Biology, vol. 146, no. 1, pp. 60-68, 2007.

[86] C. Z. Oliveira, N. A. Santos-Filho, D. L. Menaldo et al., "Structural and functional characterization of a $\gamma$-type phospholipase A 2 inhibitor from Bothrops jararacussu Snake Plasma," Current Topics in Medicinal Chemistry, vol. 11, no. 20, pp. 2509-2519, 2011.

[87] S. Lizano, B. Lomonte, J. W. Fox, and J. M. Gutiérrez, "Biochemical characterization and pharmacological properties of a phospholipase $\mathrm{A}_{2}$ myotoxin inhibitor from the plasma of the snake Bothrops asper," Biochemical Journal, vol. 326, no. 3, pp. 853-859, 1997.

[88] N. Ohkura, H. Okuhara, S. Inoue, K. Ikeda, and K. Hayashi, "Purification and characterization of three distinct types of phospholipase $\mathrm{A}_{2}$ inhibitors from the blood plasma of the Chinese mamushi, Agkistrodon blomhoffii siniticus," Biochemical Journal, vol. 325, no. 2, pp. 527-531, 1997.

[89] K. Chen, L.-P. Zhong, L.-Z. Chen, X. Li, X. Xu, and C.H. Huang, "Investigation and purification of snake venom secretory phospholipase $A_{2}$ inhibitors from sera of some common snake species in Jiangxi province," Pharmaceutical Biotechnology, vol. 18, no. 3, pp. 220-223, 2011.

[90] Z. Le, X. Li, P. Yuan, P. Liu, and C. Huang, "Orthogonal optimization of prokaryotic expression of a natural snake venom phospholipase $\mathrm{A}_{2}$ inhibitor from Sinonatrix annularis," Toxicon, vol. 108, pp. 264-271, 2015.

[91] M. E. Garcia Denegri, S. Maruñak, J. S. Todaro, L. A. PonceSoto, O. Acosta, and L. Leiva, "Neutralisation of the pharmacological activities of Bothrops alternatus venom by anti-PLA IgGs," Toxicon, vol. 86, pp. 89-95, 2014.

[92] J. P. Rodriguez, M. De Marzi, S. Maruñak, E. L. Malchiodi, L. C. Leiva, and O. Acosta, "Rabbit IgG antibodies against phospholipase $\mathrm{A}_{2}$ from Crotalus durissus terrificus neutralize the lethal activity of the venom," Medicina, vol. 66, no. 6, pp. 512-516, 2006.

[93] L. S. Fusco, J. P. Rodríguez, F. Torres-Huaco et al., "P9a(Cdt$\mathrm{PLA}_{2}$ ) from Crotalus durissus terrificus as good immunogen to be employed in the production of crotalic anti-PLA 2 IgG," Toxicology Letters, vol. 238, no. 1, pp. 7-16, 2015.

[94] M. Karakas and W. Koenig, "Varespladib methyl, an oral phospholipase $\mathrm{A}_{2}$ inhibitor for the potential treatment of coronary artery disease," IDrugs, vol. 12, no. 9, pp. 585-592, 2009.
[95] D. De Luca, A. Minucci, J. Trias et al., "Varespladib inhibits secretory phospholipase $\mathrm{A}_{2}$ in bronchoalveolar lavage of different types of neonatal lung injury," Clinical Pharmacology and Therapeutics, vol. 52, no. 5, pp. 729-737, 2012.

[96] R. S. Rosenson, M. Elliott, Y. Stasiv, and C. Hislop, "Randomized trial of an inhibitor of secretory phospholipase $A_{2}$ on atherogenic lipoprotein subclasses in statin-treated patients with coronary heart disease," European Heart Journal, vol. 32, no. 8, pp. 999-1005, 2011.

[97] M. Lewin, S. Samuel, J. Merkel, and P. Bickler, "Varespladib (LY315920) appears to be a potent, broad-spectrum, inhibitor of snake venom phospholipase $\mathrm{A}_{2}$ and a possible pre-referral treatment for envenomation," Toxins, vol. 8, no. 9, article no. 248, 2016.

[98] D. Mora-Obando, J. Fernández, C. Montecucco, J. M. Gutiérrez, and B. Lomonte, "Synergism between basic Asp49 and Lys49 phospholipase $\mathrm{A}_{2}$ myotoxins of viperid snake venom in vitro and in vivo," PLoS ONE, vol. 9, no. 10, Article ID e109846, 2014.

[99] L. D. Possani, B. M. Martin, A. Yatani et al., "Isolation and physiological characterization of taicatoxin, a complex toxin with specific effects on calcium channels," Toxicon, vol. 30, no. 11, pp. 1343-1364, 1992.

[100] S. Xiong, Y. Luo, L. Zhong et al., "Investigation of the inhibitory potential of phospholipase $A_{2}$ inhibitor gamma from Sinonatrix annularis to snake envenomation," Toxicon, vol. 137, pp. 83-91, 2017. 


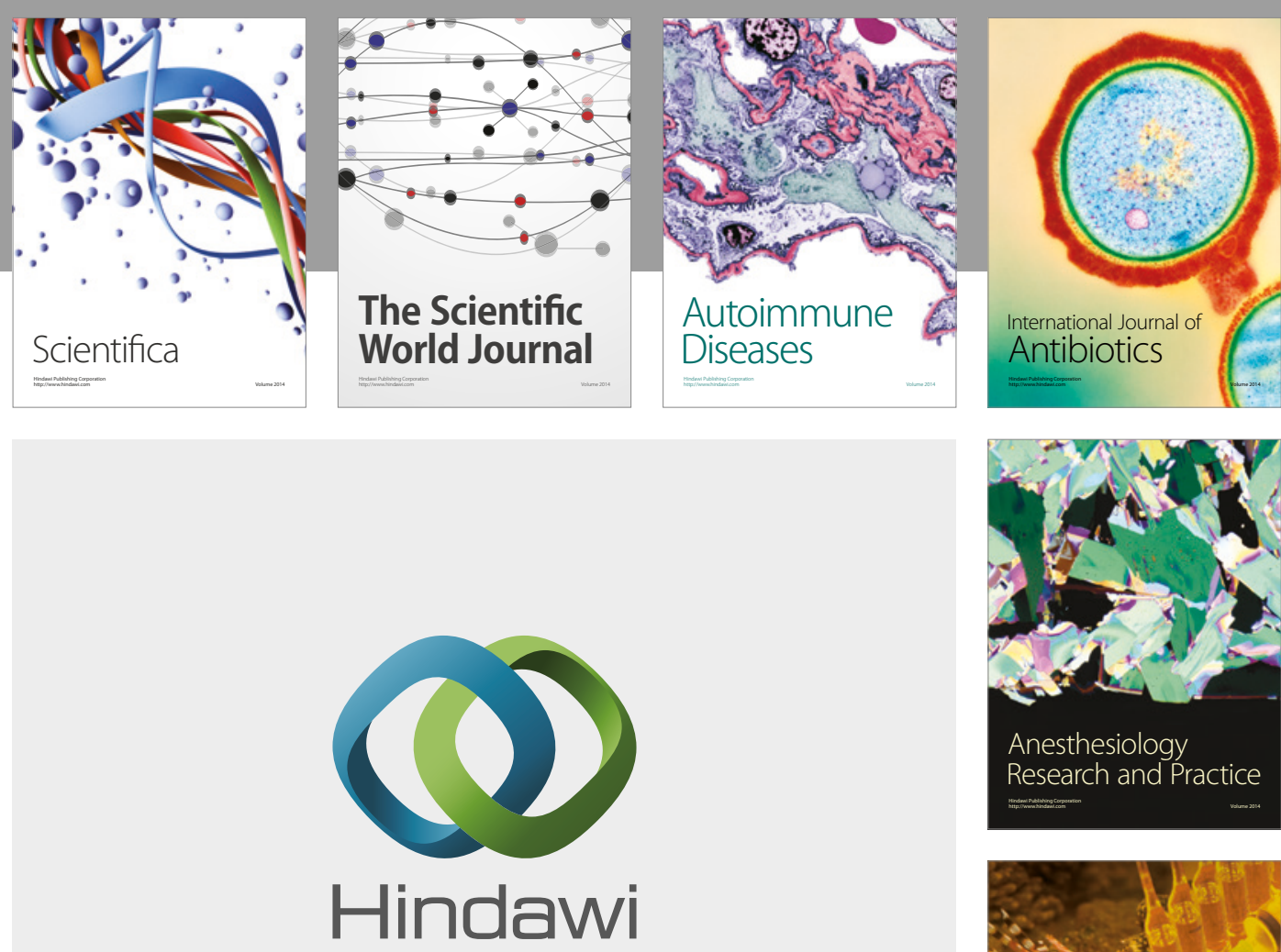

Submit your manuscripts at

https://www.hindawi.com
